\title{
Physical Exercise Protects Against Endothelial Dysfunction in Cardiovascular and Metabolic Diseases
}

\author{
Juan Gao ${ }^{1,2} \cdot$ Xue Pan ${ }^{1,2} \cdot$ Guoping $\mathrm{Li}^{3} \cdot$ Emeli Chatterjee $^{3} \cdot$ Junjie Xiao ${ }^{1,2}(\mathbb{D}$
}

Received: 15 July 2021 / Accepted: 2 September 2021 / Published online: 17 September 2021

(c) The Author(s), under exclusive licence to Springer Science+Business Media, LLC, part of Springer Nature 2021

\begin{abstract}
Increasing evidence shows that endothelial cells play critical roles in maintaining vascular homeostasis, regulating vascular tone, inhibiting inflammatory response, suppressing lipid leakage, and preventing thrombosis. The damage or injury of endothelial cells induced by physical, chemical, and biological risk factors is a leading contributor to the development of mortal cardiovascular and cerebrovascular diseases. However, the underlying mechanism of endothelial injury remains to be elucidated. Notably, no drugs effectively targeting and mending injured vascular endothelial cells have been approved for clinical practice. There is an urgent need to understand pathways important for repairing injured vasculature that can be targeted with novel therapies. Exercise training-induced protection to endothelial injury has been well documented in clinical trials, and the underlying mechanism has been explored in animal models. This review mainly summarizes the protective effects of exercise on vascular endothelium and the recently identified potential therapeutic targets for endothelial dysfunction.
\end{abstract}

Keywords Vascular disease $\cdot$ Endothelium dysfunction . Exercise $\cdot$ Therapeutic targets

\section{The Physiological Function of Vascular Endothelium}

Vascular endothelial cells (VECs) consist of a single layer of flattened cells situated longitudinally along the direction of blood flow [1-3]. An adult human is composed approximately of more than $10^{12}$ endothelial cells, which weigh approximately $100 \mathrm{~g}$ and cover a surface area of about 1000 $\mathrm{m}^{2}[1,4]$. Endothelium not only serves as a barrier between

Editor-in-Chief Enrique Lara-Pezzi oversaw the review of this article

Junjie Xiao

junjiexiao@shu.edu.cn

1 Institute of Geriatrics (Shanghai University), Affiliated Nantong Hospital of Shanghai University (The Sixth People's Hospital of Nantong), School of Medicine, Shanghai University, Nantong 226011, China

2 Cardiac Regeneration and Ageing Lab, Institute of Cardiovascular Sciences, Shanghai Engineering Research Center of Organ Repair, School of Life Science, Shanghai University, 333 Nan Chen Road, Shanghai 200444, China

3 Cardiovascular Division of the Massachusetts General Hospital and Harvard Medical School, Boston, MA 02114, USA blood and solid tissue but also is one of the most important metabolic and endocrine organs in the human body [5, 6]. Endothelium synthesizes and releases a variety of growth factors, vasodilators, vasoconstrictors, coagulation, and anticoagulation factors, playing critical roles in regulating vascular tone; inhibiting platelet activation, leukocyte adhesion, and migration; preventing thrombogenesis and inflammatory response; suppressing smooth muscle cell proliferation; promoting fibrinolysis; and maintaining the stability and integrity of vasculature [5-8].

Endothelium-derived relaxing factor (EDRF) is recognized as the most essential vasodilator, stimulated by acetylcholine (Ach), and regulates vascular tone. The function of EDRF is majorly mediated by nitric oxide (NO) $[9,10]$, which has been well studied in recent years and is majorly accepted as the most important endothelium-derived vasodilator. A critical vasoconstrictor, endothelin-1 (ET-1), has long-lasting effects on vasculature, released from endothelium [11]. Besides, endothelial cells serve as a source of physiologically important molecules, such as prostacyclin (PGI2), thrombomodulin (TM), von Willebrand factor (VWF), thromboxane A2 (TXA2), and tissue factor (TF) (Fig. 1) [4, 12]. These factors antagonize each other and maintain the vascular homeostasis. It is noteworthy that the overall vascular response to stimulation, either relaxation or contraction, will be the result of a complex interaction between different vascular regulators. 


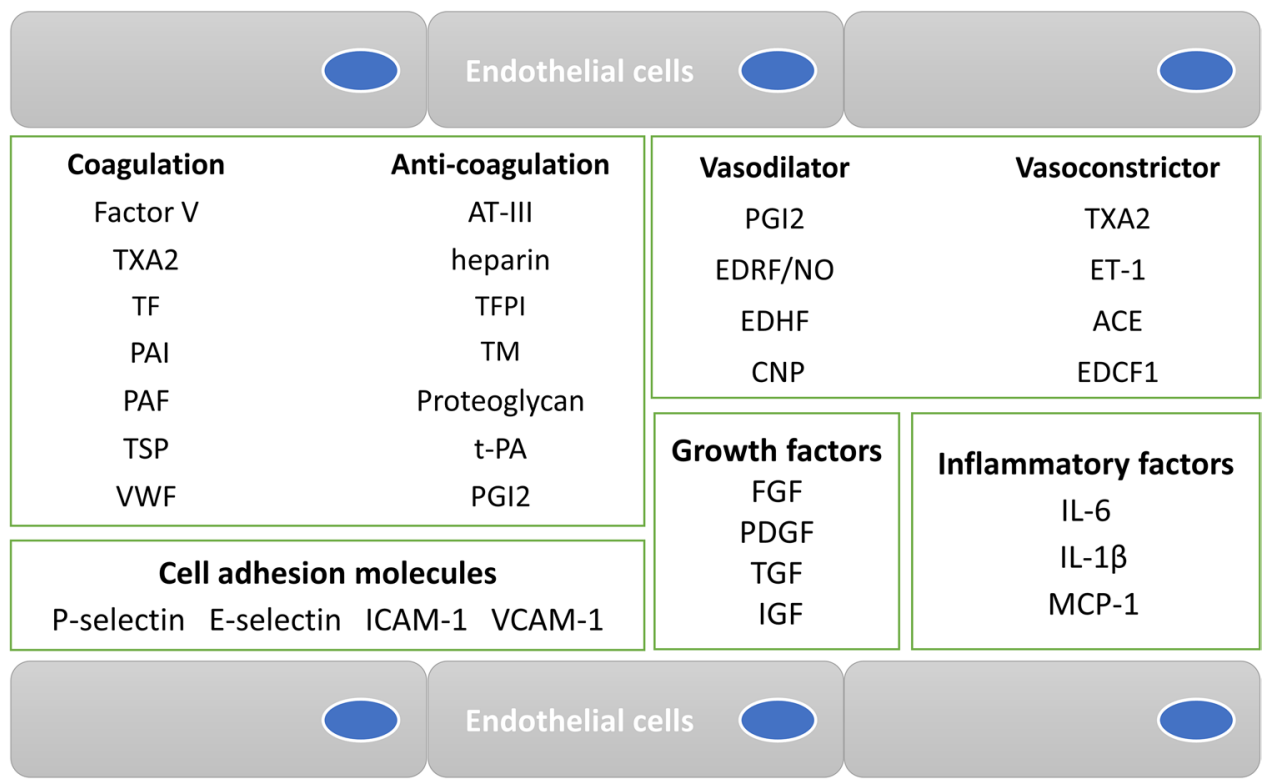

Fig. 1 Endothelium functions as an important endocrine organ. TXA2, thromboxane A2; TF, tissue factor; PAI, plasminogen activator inhibitor; PAF, platelet activating factor; TSP, thrombospondin; VWF, von Willebrand factor; AT-III, antithrombin III; TFPI, tissue factor pathway inhibitor; TM, thrombomodulin; t-PA, tissue plasminogen activator; PGI2, prostaglandin I2, also called prostacyclin; EDRF, endothelium derived relaxing factor; NO, nitric oxide; EDHF,

\section{Risk Factors of Vascular Endothelial Dysfunction and Their Effects in Different Organs}

Endothelial cells are the essential components of the circulatory system, which play critical roles in maintaining the homeostasis of different organs and tissues [13]. Different

Fig. 2 Risk factors impair endothelial function endothelium-derived hyperpolarizing factor; CNP, c-type natriuretic peptide; ET-1, endothelin; ACE, angiotensin converting enzyme; EDCF1, endothelium-derived contracting factor 1; FGF, fibroblast growth factor; PDGF, platelet derived growth factor; TGF, transforming growth factor; IGF, insulin-like factor; IL-6, interleukin-6; IL-1 $\beta$, interleukin-1 $\beta$; MCP1, monocyte chemoattractant protein-1

endothelial risk factors, such as hypertension, hypercholesterolemia, hyperglycemia, homocysteine (Hcy), and oxidized low-density lipoprotein (ox-LDL), inflammatory factors (such as interleukin-6 (IL-6) and tumor necrosis factor $\alpha(\mathrm{TNF}-\alpha)$ ), obesity, aging, estrogen deficiency, and mental stress [3,14-16] could affect vascular endothelium and subsequently damage the blood vessels (Fig. 2). Endothelial dysfunction is a hallmark of impairment of
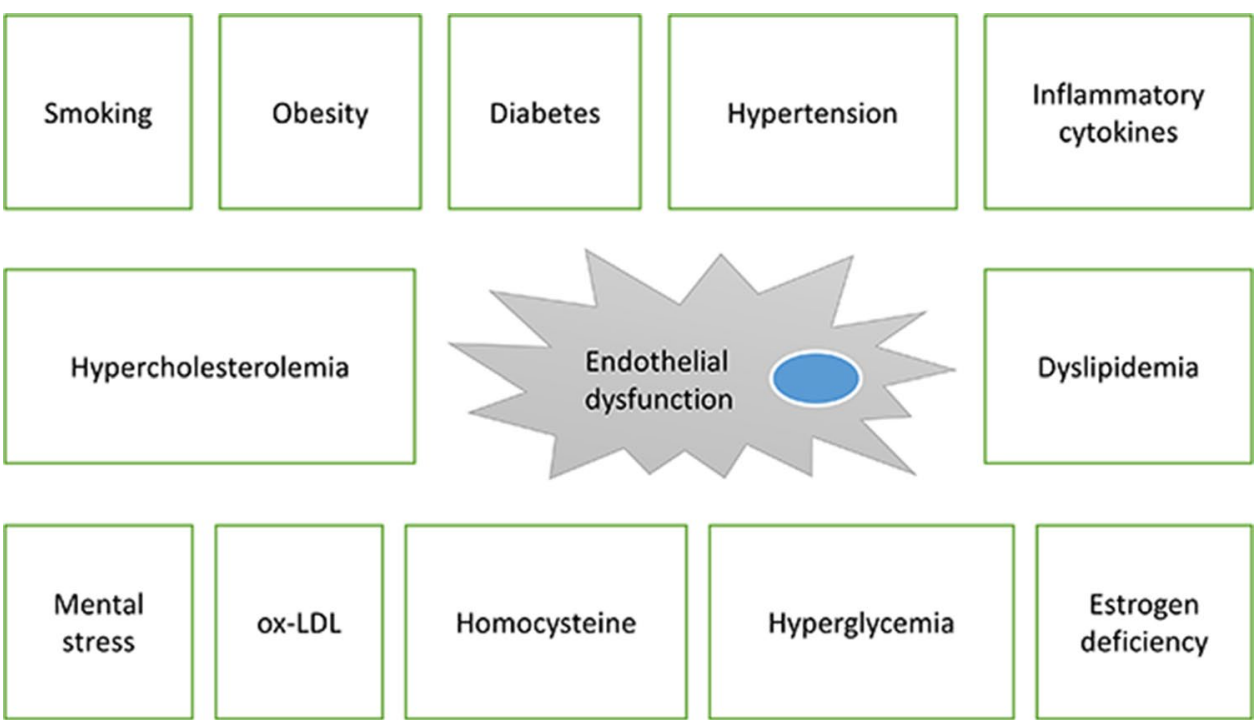

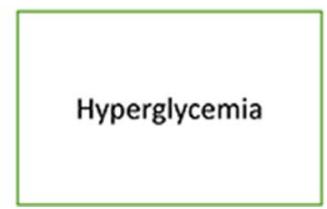

Estrogen deficiency 
vasculature and plays a pivotal role in the development of many types of human diseases $[17,18]$.

Heart harbors many types of endothelial cells, including endocardial endothelium, coronary endothelial cells, and microvascular endothelial cells, which play distinct roles in maintaining cardiac function [19]. Cardiac endothelial cells form a natural barrier between circulating blood and myocardial tissue, deliver oxygen and nutrients, remove metabolic waste, and influence cardiac growth, contractility, and rhythm [20]. Dysfunction of cardiac endothelial cells has been found to occur in atrial fibrillation, arrhythmia, cardiac hypertrophy, myocardial ischemia/reperfusion injury, and heart failure [21, 22]. Damage in coronary endothelial cells results in lower NO synthesis, higher oxidative stress, inflammation and lipid deposition, abnormal smooth muscle proliferation and remodeling, and possibly coronary thrombosis and has been considered as an early stage of cardiac dysfunction and heart failure [23].

Lung alveolus, the gas exchange machinery, consists of multiple types of cells, including epithelial, endothelial, and mesenchymal cell lineages [24]. Pulmonary endothelial cells are important regulators in the lung alveolus that allow oxygen and carbon dioxide to exchange between blood and air. Pulmonary endothelial cells injury contributes to the development and progression of pulmonary diseases, such as pulmonary arterial hypertension (PAH), chronic obstructive pulmonary disease (COPD), and coronavirus disease 2019 (COVID-19) [25].

Cerebrovascular endothelial cells are components of both the neurovascular unit and the blood-brain barrier [26]. Damage in cerebrovascular endothelial cells is tightly correlated with the progression of cerebrovascular diseases. The blood-brain barrier, formed by brain capillary endothelial cells and covered by the basement membranes, surrounded by astrocytes end-feet and pericytes, has been shown to be critically involved in the regulation of the molecular exchange between brain parenchyma and blood flow. Blood-brain barrier dysfunction has been found to be involved in many types of neurological diseases, including Alzheimer's disease, cerebral adrenouleukodystrophy, and amyotrophic lateral sclerosis [13]. Small vessel diseases due to the endothelial dysfunction occurred in cerebral microvessels, including arterioles, capillaries, and venules, cause various lesions and abnormalities, such as white matter hyperintensities, subcortical infarcts, and lacunes seen on brain imaging $[27,28]$.

Kidney consists of remarkably diversified endothelial cell populations, including the glomerular endothelium, the endothelium of large and small vessels, and microvascular endothelium in peritubular capillaries [29]. The glomerular endothelial cells, highly fenestrated and covered by a rich glycocalyx, are involved in the podocyte structure and glomerular filtration property maintenance. The large and small vessel endothelium contributes to the renal vasculature. The microvascular endothelium is involved in tubular secretion and reabsorption. Renal endothelium possesses varied functions, and damage in them implicates in many types of kidney diseases, such as atypical hemolytic uremic syndrome (ahus), glomerulonephritides, acute kidney injury (AKI), and renal failure [30]. The endothelial-to-mesenchymal transition (EndMT) process is the key driver of renal fibrosis and the development of chronic kidney disease [31].

Liver sinusoidal endothelial cells (LSECs) are highly specialized and localized at the interface between blood cells and hepatocytes [32]. LSECs play pivotal roles in regulating hepatic vascular tone, keeping the low portal pressure, preventing Kupffer cell and hepatic stellate cell activation, and maintaining liver homeostasis. Dysfunction of LSECs is recognized as the early event in the progression of chronic liver diseases. Injury of LSECs increases ET-1 level and decreases NO level, activates hepatic stellate cells, promotes renal fibrosis, increases intrahepatic resistance, and leads to large array of liver diseases [33, 34].

Mechanistically, the endothelium deterioration is caused mainly by inadequate release of $\mathrm{NO}$ and excessive oxidative stress. The NO is constitutively generated by NO synthase (NOS) from oxygen and L-arginine in endothelial cells. There are three different isoforms of NOS, endothelial NOS (eNOS), neuronal NOS (nNOS), and inducible NOS (iNOS) [35]. eNOS is constitutively expressed in endothelium and catalyzes the synthesis of NO, which diffuses into the vascular smooth muscle cells, activates soluble guanylate cyclase (GC), and induces vascular relaxation. iNOS is activated under pathological conditions, produces excessive NO of short duration and exhausts the L-arginine substrate, and eventually leads to insufficiency of NO. Moreover, excessive NO derived from high levels of iNOS interacts with reactive oxygen species (ROS) and causes endothelial oxidative damage [36].

ROS is generated by vascular endothelial cells that include superoxide, hydrogen peroxide, peroxynitrite, hydroxyl radicals, and some free radicals. It is known that a small amount of ROS such as $\mathrm{H}_{2} \mathrm{O}_{2}$ serves as a positive signaling molecule to trigger $\mathrm{NO}$ generation under physiological conditions. However, excessive ROS in the blood vessel results in the endothelial dysfunction and the activation of inflammatory response [37]. Thus, maintaining ROS at a proper level by precise regulatory mechanisms is very important to keep endothelium integrity. NAD(P) $\mathrm{H}$ oxidase (NOX) acts as the main contributor of vascularderived ROS and is upregulated in the arteries of patients with diabetes and obesity. Increased NOX activity results in the oxidation of tetrahydrobiopterin (BH4), an eNOS essential cofactor, which causes eNOS dimers to separate and produce superoxide instead of NO. The production of superoxide by eNOS, called uncoupling, leads to decreased 
NO bioavailability and oxidative stress [37]. There are several types of reductases to counteract NOX activity and prevent oxidative stress, such as superoxide dismutase (SOD), catalase, and glutathione sulfur transferase (GST). However, excessive ROS stimulated by risk factors reduces the activity of antioxidant enzymes and impairs the antioxidant defense system [37, 38].

\section{Roles of the Endothelium in Metabolic Homeostasis}

The endothelium is a dynamic organ and could be divided into arterial, venous, capillary, and lymphatic subtypes according to their architectures and functions [29]. Accumulating data indicates that vascular endothelium plays a pivotal role in the regulation of metabolic homeostasis [39]. Numerous studies support that hypercholesterolemia, hyperglycemia, Hcy, ox-LDL, and other metabolic stresses critically contribute to endothelial dysfunction and the resulted vascular diseases. In normoxia, all the endothelial cell types are highly glycolytic and exhibit a comparable glucose utilization as some cancer cells and a much higher glycolytic flux in tumor endothelial cells [40]. Endothelial cells remain at a quiescent state for years, while they could switch rapidly into a highly proliferative and migratory state, namely angiogenic state, during vessel sprouting. It was found that metabolism in endothelium differs between quiescent state and angiogenic state, between normal state and pathological vasculature, and among different endothelial cell types [41]. A histochemical study in coronary arteries and arterioles and another study in renal arteries and arterioles both suggest that the metabolism in these arteries is predominantly aerobic in nature $[42,43]$. Fatty acids might be the major energy source in coronary arteries, while limited lipid catabolism was indicated in renal arteries [42, 43]. Another study with chronic epinephrine intoxicationinduced vascular remodeling in rabbits found that changes in energy metabolism differed in arteries and veins: There are decreased oxygen consumption and increased lactic acid and ATP production in arteries, while in veins, these deficiencies were either present as significantly lower amount or remained absent [44]. Capillaries are the smallest blood vessels and the connection between veins and arteries, playing essential roles in substance exchange and metabolism homeostasis. Capillaries are capable of sensing and responding to vasoactive stimuli, coupling local blood flow with local metabolism, and ensuring blood flow matches with capillary exchange [45].

The O subfamily of forkhead (FoxO) 1 has been found to be a crucial regulator of glucose and lipid metabolic pathways in many organs and tissues, including endothelium [46]. FoxO1 is a downstream effector of the phosphatidylinositol-3-OH kinase (PI3K)/AKT and is involved in the regulation of both cell growth and cellular metabolism. PI3K/AKT phosphorylates FoxO1, impedes its nuclear localization, and inhibits its function as a transcription factor [47]. Many factors in endothelium affect FoxO1 activity or post-translation modification. Insulinsignaling cascade deregulation is correlated with the reduction of FoxO1 phosphorylation. SIRT1, known as NAD-dependent deacetylase sirtuin-1, regulates FoxO1 via its deacetylase activity, promoting its effect in angiogenesis and metabolic remodeling [48]. The overexpression of nuclear FoxO1 isoform in human umbilical endothelial cells (HUVECs) has been found to increase endogenous eNOS inhibitor dimethylarginine (SDMA and ADMA) levels, decrease NO production, and increase inflammation and oxidative stress [46]. Specific depletion of FoxO1 in endothelium has been found to promote endothelial proliferation and glucose metabolism, indicating that FoxO1 plays pivotal roles in controlling angiogenic and glycolytic capacities and maintaining energy homeostasis in endothelium [49].

\section{Diagnosis of the Vascular Endothelial Dysfunction in Clinical Practice}

Endothelial dysfunction is considered the initial step of atherosclerosis and many other vascular diseases that precedes the detection of structural abnormality and plaque formation observed by high-resolution ultrasound or angiography $[16,21]$. Effectively retarding or reversing the vascular endothelial dysfunction in the early stage appears to be promising therapeutic strategies to prevent vasculature from further deterioration and formation of lethal vascular diseases [8]. Therefore, the effective and precise diagnosis of the endothelial dysfunction is recognized as a key issue in clinical practice.

The most common method used to measure endothelial dysfunction is endothelium-dependent flow-mediated vasodilatation (FMD) measured by high-resolution ultrasound [50]. Nowadays, measurement of FMD in a conduit artery (commonly brachial artery) or measurement of the FMD stimulated by agonist Ach has been used as an endothelial dysfunction index in many clinical settings. These are non-invasive methods and can be performed in outpatient clinics [51]. An increase in blood flow and shear stress by agonist or exercise activates eNOS activity, causes vasodilator NO generation, and eventually results in FMD changes. Comparison of the FMD index could reflect 
endothelial function and the NO bioavailability of the conduit artery. Low FMD in the brachial artery mainly reflects the endothelial damage in macrovascular vessels [52]. It is well documented that microvascular endothelial damage is formed before the macrovascular injury and could act as an early marker of vasculature damage [21]. Based on the peripheral arterial tonometry (PAT) technology, reactive hyperemia index (RHI), another non-invasive method, is now developed to be a reliable strategy and is utilized to assess the damage of microvascular endothelium [52, 53]. RHI has been found to be correlated with flow-mediated dilation (FMD) and is comparable for evaluating endothelial dysfunction [53].

Circulating endothelial cells (CECs) are derived from damaged vasculature through direct detachment from the blood vessel in response to many risk factors and mechanical injury. CEC count is an important and acceptable index for the assessment of endothelial dysfunction [54, 55]. Different from the other circulating markers detected in the plasma of peripheral blood, the enrichment of CECs is the only direct cellular marker of endothelial dysfunction. More importantly, increased CEC counts is associated with increased severity of vascular disease and worsened prognosis, indicating a potential correlation between increased CEC counts and disease burden [54].

Endothelial damage markers implicate adverse vascular changes, including arterial vasomotor control, prothrombogenic status, pro-inflammatory states, impaired fibrinolysis, and the imbalance between cell proliferation and cell death [54]. Except for lower FMD index and increased CEC counts, the elevation of many other markers in peripheral blood, such as endothelin-1 (ET-1), von Willebrand factor (vWF), soluble E-selectin (sEsel), soluble intercellular cell adhesion molecule 1 (sICAM-1), and soluble vascular cell adhesion molecule 1 (sVCAM-1), also reflects the severity of the endothelial injury and could be used as the predictors of vascular diseases [15, 54].

\section{Rescue Endothelial Injury by Physical Exercise}

Cardio-metabolic benefits of exercise in many cardiovascular diseases have been well documented in epidemiological and clinical studies $[35,56]$. Exercise was found to reduce the incidence of high blood pressure, diabetes, and stroke. Until now, physical exercise was fully accepted and taken as a non-drug therapeutic strategy to use both in disease prevention and disease treatment [57]. Numerous studies in clinical trials and animal models showed that exercise exerts endothelial protection and helps in retaining the endothelial function (Fig. 3) [58-60].

In response to exercise, the working skeletal muscle consumes more oxygen and energy, which results in elevated cardiac contractility, heart rate, blood pressure, blood flow, and endothelium-dependent vasodilation, to meet the oxygen and
Fig. 3 The underlying mechanism of the exercise in the protection of endothelial dysfunction

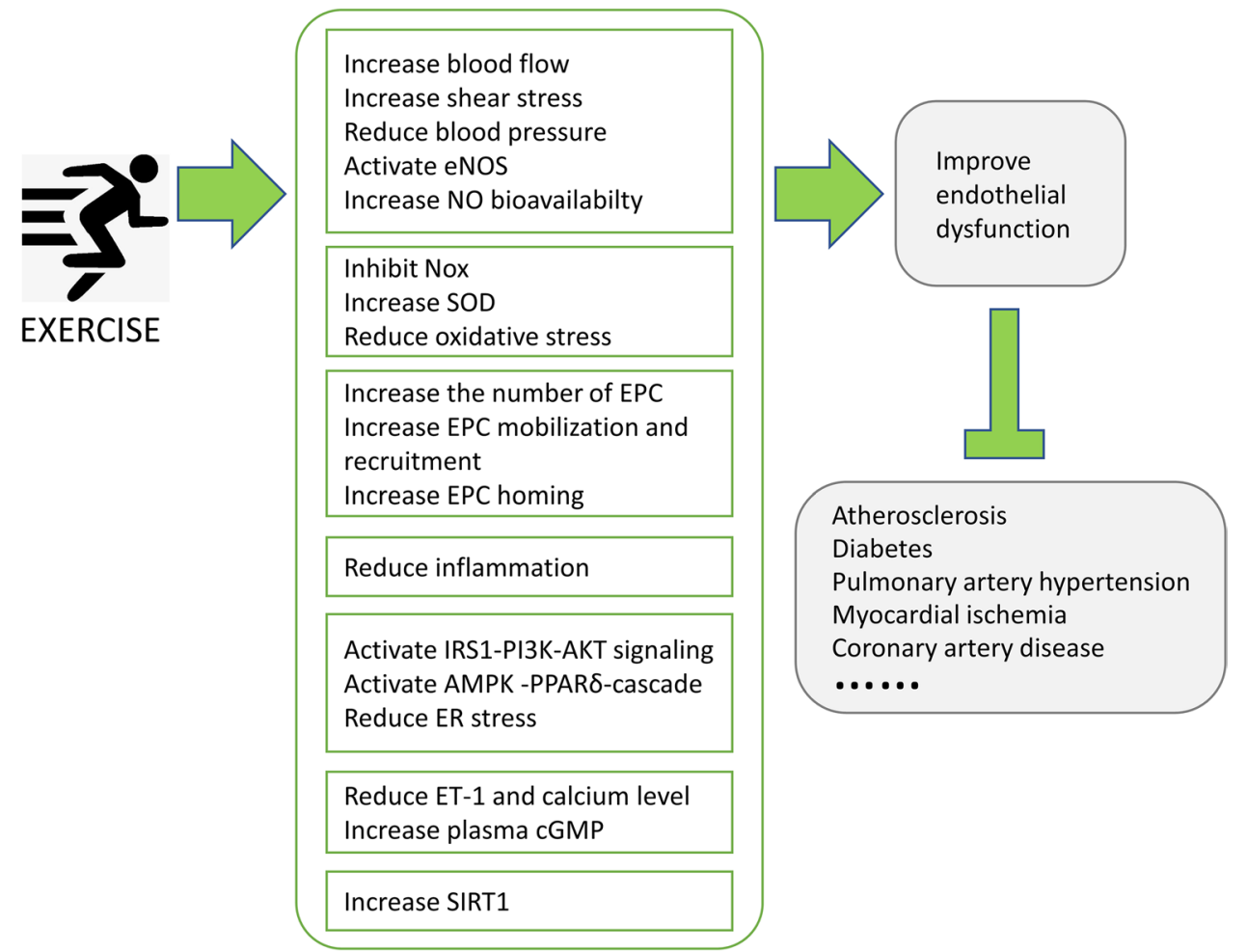


energy demand [35, 61]. Exercise-induced ischemic metabolites of the vascular system would cause the generation and elevation of ROS. However, the overall net effect of long-term exercise will ultimately improve the tolerance of oxidative stress and mitigate the oxidative burden. Apocynin, a NOX inhibitor, has been found to reduce ROS level and reverse microvascular endothelial injury in obese subjects. The animal studies using apocynin and other antioxidants suggested that aerobic exercise decreases oxidative stress and preserves endothelial function through inhibiting NOX activity [62]. It was also found that shear stress induced by excise increases NO bioavailability, which plays a critical role in regulating ischemic metabolites in skeletal muscle during exercise. The augment of shear stress activates the eNOS activity, increases NO production, and improves endothelial function.

Exercise has been undisputedly recognized to stimulate NO production and protect against endothelial damage. However, it remains unclear how exercise-elevated shear stress is translated to the signal of NO generation [63]. Various types of growth factors have been found to be induced by exercise and released into the circulation system, including insulin-like growth factor 1 (IGF1), platelet-derived growth factor (PDGF), and vascular endothelial growth factor (VEGF) [35]. In response to exercise, IGF1-IGF1 receptor (IGF1R)-insulin receptor substrate (IRS) is capable of activating PI3K-AKT signaling pathway, which plays a key role in maintaining optimal vascular function [64]. After binding to IGF1R, IGF1 subsequently recruits the IRS1/IRS2, which activates PI3K-AKT signaling and increases AKT-mediated eNOS phosphorylation and NO production. VEGF binds to the VEGF receptor (VEGFR1/VEGFR2) on the surface of endothelium and activates PI3K-AKT signaling, which further enhances endogenous angiogenesis and vascular wound healing [35, 64].

On the contrary, animal studies have found that inhibition of NOS resulted in reduced blood flow within exercising skeletal muscles and decreased exercise capacity. Similar results were found in patients with chronic kidney disease (CKD) or heart failure (HF). Low FMD detected in these patients reflects inadequate $\mathrm{NO}$ release derived from injured endothelium. Reduced NO bioavailability causes abnormal blood flow within the working skeletal muscles and is associated with impaired exercise capacity measured by $\mathrm{VO}_{2}$ peak in these patients, which could be used as a predictor of vasculature damage $[61,65]$.

\section{The Beneficial Effects of Exercise on Endothelial Progenitor Cells}

The endothelium is a self-renew system; however, disruption of the injury and repair balance of endothelium will lead to the pathophysiology of vascular diseases. The endothelial injury can be repaired by endothelial cell proliferation, the differentiation of endothelial progenitor cells (EPCs) to endothelial cells, and other mechanisms [66, 67]. There is a study in 1997 showing for the first time that human peripheral blood-derived EPC is one kind of stem cells which plays important role in endothelial repair and angiogenesis [68]. Endothelial injury triggers the mobilization of EPCs from the bone marrow to the damaged region and is rescued via EPC proliferation and differentiation [69]. Many studies have found that the pathogenesis of various vascular diseases (such as diabetes, hypertension, and atherosclerosis) is related to EPC aging [11], within which EPCs show lower capacity of migration, adhesion, and angiogenesis and weakened vascular endothelial reparability. There are a series of reported strategies targeting EPCs to repair damaged endothelium, such as direct EPC transplantation or in vivo stimulation of EPC mobilization and proliferation [70-72]. Certain drugs, including aspirin, resveratrol, rosiglitazone, and pyrrolidone, have been found to improve EPC mobilization and delay the aging of EPC. Subramaniyam et al. found that granulocyte-macrophage colony-stimulating factor (GM-CSF) treatment could mobilize the EPCs, repair the endothelial dysfunction, and restore the injured vascular tissue in patients with peripheral arterial disease (PAD) [73]. Growing evidence showed that exercise training (ET) enhances endothelial renewal, induces EPC mobilization from the bone marrow niche, promotes homing of EPC to damaged vascular sites, and eventually counteracts endothelial dysfunction [74, 75]. In one clinical trial, twenty patients with documented coronary artery disease (CAD) and/or cardiovascular risk factors (CVRF) were recruited to join a 12-week supervised exercise training (SET). The beneficial effects of SET on endothelium were demonstrated by the increased number of circulating EPC, elevated NO production, and improved FMD of the brachial artery in training group patients [76]. In another clinical research, 40 PAD patients under medical treatments were randomly assigned to SET group or control group. It was found that 6 months of SET increases the number of circulating EPC and decreases the plasma levels of asymmetric dimethylarginine (ADMA, an inhibitor of NOS), both reflecting improved endothelial function [77]. In addition, 37 patients with ST-elevation myocardial infarction (STEMI) were randomized to an ET group or a matched sedentary group (control). Consistently, after regular ET, the number and the migration capacity of circulating progenitor cells (CPCs) were increased, the brain natriuretic peptide (BNP) level was decreased, and $\mathrm{VO}_{2}$ max was elevated [78]. Overall, all these clinical trials listed above and others indicate that exercise protects against endothelial dysfunction by targeting EPCs. 


\section{The Beneficial Effects of Exercise on Endothelial Dysfunction in Coronary Artery Disease and Chronic Heart Failure}

Endothelial dysfunction is a key feature of CAD and chronic heart failure (CHF). Numerous clinical trials showed that ET is an effective countermeasure for the injured endothelium in CAD and CHF patients [79]. The protective effects of 4 weeks of ET on endothelial dysfunction in patients with CAD (10 training patients and 9 control patients) were demonstrated by the improvement of Ach-induced vasoconstrictive responses and the increased mean peak flow velocity both in epicardial coronary vessels and in resistance vessels [80]. Another clinical trial showed that 8 weeks of ET rescued endothelium function as demonstrated by improved FMD in stable CAD patients (32 exercisers and 32 control), but with no changes of inflammation, oxidative stress, and endothelial progenitor cell [81]. The effects of 12 weeks of endurance ET on endothelial function were investigated in eighteen patients with CAD and found an improvement of FMD, the augmentation of plasma nitrite and SOD activity, and the reduction of oxidative stress [82]. Forty patients with CAD were recruited to participate in a supervised cardiac rehabilitation program for 10 weeks of moderate-intensity leg exercise and 18 matched sedentary control. Endothelium-dependent FMD in a conduit artery of the leg but not the arm was significantly improved, and nitroglycerinmediated dilation in the upper arm and lower extremity was unaffected [83]. Clinical studies in 45 patients with CAD showed that ET could mitigate endothelial dysfunction by reducing vascular expression of NOX, angiotensin II (Ang II) receptor type I $\left(\mathrm{AT}_{1}-\mathrm{R}\right)$, and decreasing ROS generation [84]. Compared with 18 matched control, ET in 17 stable CAD patients significantly improved endothelial function, which may be closely related to shear-stress induced phosphorylation of eNOS at Ser 1177 residue by AKT [85].

Forty-one patients (24 exercisers and 17 non-exercisers) with a recent myocardial infarction after successful percutaneous coronary intervention (PCI) surgery were recruited to study the protective effect of exercise on endothelial restoration. The mean change of coronary artery diameter induced by Ach infusion showed that 6 months of regular exercise improved endothelial function in the coronary arteries [86]. CoQ10 is an essential component of mitochondria and plays an important role in cell respiration, ATP generation, and cellular metabolism and has antioxidant properties. Twenty-three CHF patients were recruited to clinical research to investigate the effect of CoQ10 and/or ET on endothelial dysfunction. Oral $\mathrm{CoQ} 10$ or ET improves peak $\mathrm{VO}_{2}$, endothelial function, and left ventricular contractility, and ET along with CoQ10 significantly enhanced these effects [87]. Serum levels of GM-CSF, macrophage chemoattractant protein-1 (MCP-1), sICAM-1, and SVCAM-1 were assessed in 12 patients with stable CHF before and after a 12-week ET [88]. All these markers, critically involved in monocyte/ macrophage-endothelial interaction, peripheral inflammation, or endothelial injury, were found to be downregulated by ET. In another clinical trial, patients with recent myocardial infarction were assigned to 4 groups: aerobic ET $(n=52)$, resistance ET $(n=54)$, resistance plus aerobic ET $(n=53)$, and control $(n=52)$, to investigate the effects of different types of ET and followed by detraining on endothelial function. It was found that ET is associated with improved endothelial function, which was demonstrated by increased FMD and decreased VWF levels in all studied types of ET. However, the beneficial effects disappeared after 1 month of detraining [65], indicating that the beneficial adaptive changes induced by exercise in these patients might be reversible. Many researchers have conducted extensive research on the preventive and therapeutic effects of ET in many types of diseases; however, a few studies have explored in-depth whether these beneficial effects induced by exercise are permanent or transient. Moreover, many diseases such as HF combined with skeletal muscle atrophy are characterized as exercise intolerance [89]. Endothelial dysfunction also exhibits decreased exercise capacity. Thus, further efforts are still needed to explore the key exercise sensors as novel therapeutic targets and exercise mimetic drugs for the prevention and treatment of vasculature damage.

\section{Physical Exercise-Induced Improvement of the Endothelium in Diabetes and Obesity}

Diabetes or diabetes mellitus (DM) is characterized by high blood sugar level-induced long-term metabolic disorders [90]. There are two types of diabetes, type 1 and type 2 . Type 1 diabetes is caused by insufficiency of insulin, while type 2 diabetes normally results from insulin resistance or insulin insensitivity. Until now, the most effective way to avoid type 2 diabetes remains old-fashioned healthy dietary and regular physical exercise [91-93]. Twenty-three patients with type $2 \mathrm{DM}$ were randomly assigned to 6 months of multifactorial intervention with a focus on ET (1 month inhospital and 5 months of home-based exercise) or matched sedentary control [94]. Vigorous ET significantly improved endothelial function, demonstrated by improvement of Achand adenosine-induced coronary vasoconstriction, beneficial changes of markers of insulin sensitivity, hyperglycemia, and inflammation both in serum and in skeletal muscle biopsies [94]. Studies in genetically diabetic mouse models 
$(\mathrm{db} / \mathrm{db})$ have been invaluable to allow researchers to identify key regulators involved in exercise-induced protection of endothelium [38, 95]. A study in diabetic mice showed that exercise restored endothelial vasodilation in response to Ach and insulin sensitivity impairment. Exercise upregulated superoxide dismutase (SOD1, SOD2) activity and phosphorylation of eNOS at ser1177 residue and increased NO bioavailability and downregulated TNF- $\alpha$ and IL-6 (two chronic inflammatory factors) levels. These results indicate that exercise exerts multiple effects on healthy protection [38]. Another study in $\mathrm{db} / \mathrm{db}$ or wild-type mice showed that exercise could improve endothelium-dependent relaxation in wild-type mice aortae, rescue flow-mediated dilation, and improve insulin-induced relaxation in mesenteric arteries in diabetic mice [95]. Therefore, it was evident that exercise training not only could restore the injured endothelial function in diabetic mice but also could improve endothelial function in wild-type mice.

Recently, an important metabolic regulator, AMPactivated protein kinase (AMPK), has become one of the research hotspots. AMPK is an evolutionarily conserved serine/threonine-protein kinase, which phosphorylates multi-substrates and participates in the energy homeostasis and metabolism regulation [96, 97]. Studies in endothelial AMPK-specific knockout mice showed that endothelial AMPK (eAMPK) plays a critical role in regulating blood flow, mediating endothelium-derived hyperpolarization response, and regulating blood pressure [98]. AMPK has been found to be upregulated by exercise and subsequently increase peroxisome proliferator-activated receptor $\delta$ (PPARס) activity. AMPK/PPARס synergistically reduces endoplasmic reticulum (ER) stress and oxidative stress, which contributes to exercise-induced protection of vascular endothelium in aortae in diabetic mice [95]. Another study of the same group found that metformin could be used as a mimetic of exercise-induced protection benefits on endothelium through the elevation of AMPK/PPAR $\delta$ signaling cascade [99]. All these aforementioned studies demonstrate that AMPK/PPAR $\delta$ might serve as a potential effective target for treating diabetic vasculopathy $[100,101]$.

\section{Physical Exercise-Induced Protection of Endothelium in Aging People}

Aging is accompanied with organ degeneration and elevated endothelial damage [102]. Studies using the aging rat models showed that aerobic exercise training could restore endothelial dysfunction $[36,103]$. Physical exercise could improve endothelial function by increasing eNOS levels and reducing inflammatory factors such as IL-6 and TNF $\alpha$ [36]. SIRT1 could promote eNOS activity through its deacetylation function. SIRT1 expression was found to be elevated by physical exercise and to correct abnormal acetylation modifications on eNOS under aging- or obesity-induced metabolic stress conditions [36]. Compared to aging men, aging women are diagnosed with estrogen deficiency, and the treatment with estrogen therapy was found to mitigate endothelial injury [104]. Ovariectomized rat model was utilized to study the effect of loss of estrogen on endothelial function and the exercise-induced protection [104]. It was found that compared to the estrogen supplement method, exercise training could reduce ET-1 and calcium level (an index of arterial stiffness), rescue NO synthesis impairment, and improve endothelial function [104]. Similar results were obtained in the study in aging women. Regular aerobic endurance exercise could significantly increase NO production and plasma cGMP (a second messenger of NO) concentration, reduce blood pressure, and decrease plasma ET-1 concentration $[105,106]$. Thus, compared to the estrogen therapy, exercise may serve as a better effective therapy for protecting aging women from endothelial dysfunction [107].

\section{The Function of miRNA in Exercise-Induced Protection of the Endothelium}

microRNA is indicated to play important functions in many types of cardiovascular diseases, and physical exercise could induce the activation/inhibition of a series of microRNAs and exert protective effects on endothelium or vasculature (Fig. 4) [108, 109]. miR-155 has been found to be significantly upregulated in atherosclerotic plaques, which regulates vascular smooth muscle cell (VSMC) proliferation and endothelial function by targeting eNOS and preventing NO production [110,111]. Recent studies found that miR-155 was downregulated by physical exercise. Another study found that simvastatin (a hydroxymethylglutaryl-coenzyme A (HMG-CoA) reductase inhibitor) could restore eNOS expression and reduce miR-155 level, indicating that miR-155 interfered with the simvastatin-induced eNOS upregulation [36]. Therefore, the reduction of miR-155 either by drugs or exercise would be beneficial to endothelial dysfunction. miR-126 is highly expressed in endothelial cells and positively regulates the function of endothelial cells by targeting high-mobility group box 1 (HMGB1), increasing NO production, and inhibiting the inflammatory response and ROS production [112]. Aerobic exercise can increase the miR-126 level and RHI index and decrease serum risk factors such as ox-LDL and blood glucose in obese adolescents [21]. miR-214 has been found to be involved in endothelial protection and angiogenesis [113] and was reported to protect against endothelial cell apoptosis possibly by targeting cyclooxygenase-2 (COX-2) [114, 115]. Another study in obese adults found that 2 months of ET and dietary intervention 


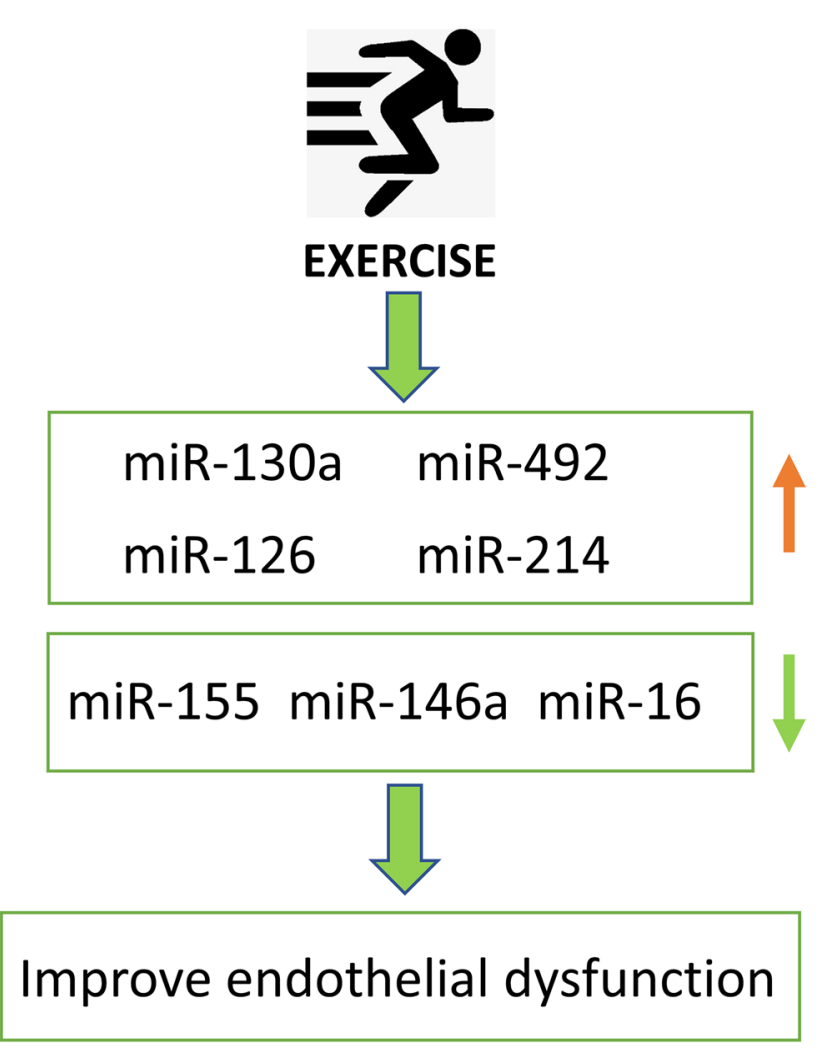

Fig. 4 miRNAs regulated by exercise in the protection of endothelial dysfunction

increased circulating miR-214 and miR-126 levels along with improved endothelial function. The association between the relative levels of EPC and miR-214 and the association between the relative changes of miR-126 with endothelial NOS were both significant [116]. miRNA16 has been reported to inhibit endothelial function and angiogenesis both in vitro and in vivo by targeting vascular endothelial growth factor receptor-2 (VEGFR2) and fibroblast growth factor receptor-1 (FGFR1) [117]. Recently, miRNA-16 was found to be significantly downregulated by aerobic exercise training in obese animals and was associated with increased VEGF expression and revascularization [118]. miR-492 has been found to be upregulated by swimming in aortic endothelium and to restore endothelial function and delay the progression of atherosclerosis by diminishing the level of resistin in aortic endothelium [119]. miR-130a inhibition has been reported to promote endothelial progenitor cell dysfunction in diabetic patients by targeting Runx3 [120]. miR-146a has been identified as senescence-associated pro-inflammatory factor which is involved in vascular remodeling [121]. Study in 19 type 2 diabetes patients showed that 3 months of exercise could significantly upregulate the expression of miR-130a and downregulate miR-146a level in circulating angiogenic cells (CACs), reduce oxidative stress, and improve endothelial functionality [122].

\section{Mending Endothelial Injury in Clinical Trials}

Endothelial dysfunction is a major risk factor of cardiovascular disease and is mainly caused by insufficient NO level and excessive oxidative stress. So, reversal of these adverse changes could be a potential therapeutic approach to restore endothelial dysfunction. However, there is still a dearth of specific drugs for restoring endothelial function in clinical practice. It was also evident that patients recovering from cardio-cerebral vascular diseases might result from the restoration of endothelial dysfunction.

Besides exercise training, many types of drugs and dietary strategies are studied in clinical trials (Table 1). Unhealthy dietary is a risk factor of endothelial dysfunction. Calorie restriction without affecting the normal nutrition is one kind of method to rescue endothelial injury. Calorie restriction could preserve NO bioavailability and maintain endothelium-dependent vascular relaxation. Statin, a HMGCoA reductase inhibitor, was found to improve endothelial function [36, 103]. Statin could alleviate oxidative stress of the endothelium, stabilize eNOS mRNA molecules, promote PI3K-AKT-mediated ser1177 phosphorylation of eNOS, increase eNOS activity, inhibit ET-1 production, downregulate iNOS activation, prevent inflammatory factors, and thus improve endothelial function [103, 123, 124]. The xanthine oxidase (XO) system generates superoxide anions in the endothelium, and inhibition of XO with allopurinol (a XO inhibitor) has been found to improve endothelial dysfunction by preventing the formation of superoxide free radicals and reducing oxidative stress in patients with Class II-CHF in a double-blind crossover clinical study [125]. BH4 is an essential cofactor of the NOS, and BH4 deficiency is associated with endothelial dysfunction. Systematic BH4 administration restores coronary microvascular dysfunction in patients with hypercholesterolemia [126]. Patients with CAD exhibit endothelial dysfunction which might be associated with procoagulant and exercise-induced platelet activation. In addition to aspirin, long-term low molecular weight heparin (Parnaparin) or placebo was administrated to 29 patients with CAD to investigate whether endothelial dysfunction-induced myocardial ischemia can be improved [127]. Parnaparin treatment in patients with stable CAD significantly decreased fibrinogen level, improved exercise intolerance, and attenuated symptoms of angina pectoris. VEGF is an essential angiogenesis growth factor and was found to improve endothelial function in patients with PAD [128, 129]. Adenovirus-mediated gene therapy to deliver angiogenic growth factors VEGF to skeletal muscles resulted in improvement of peripheral endothelial function. 


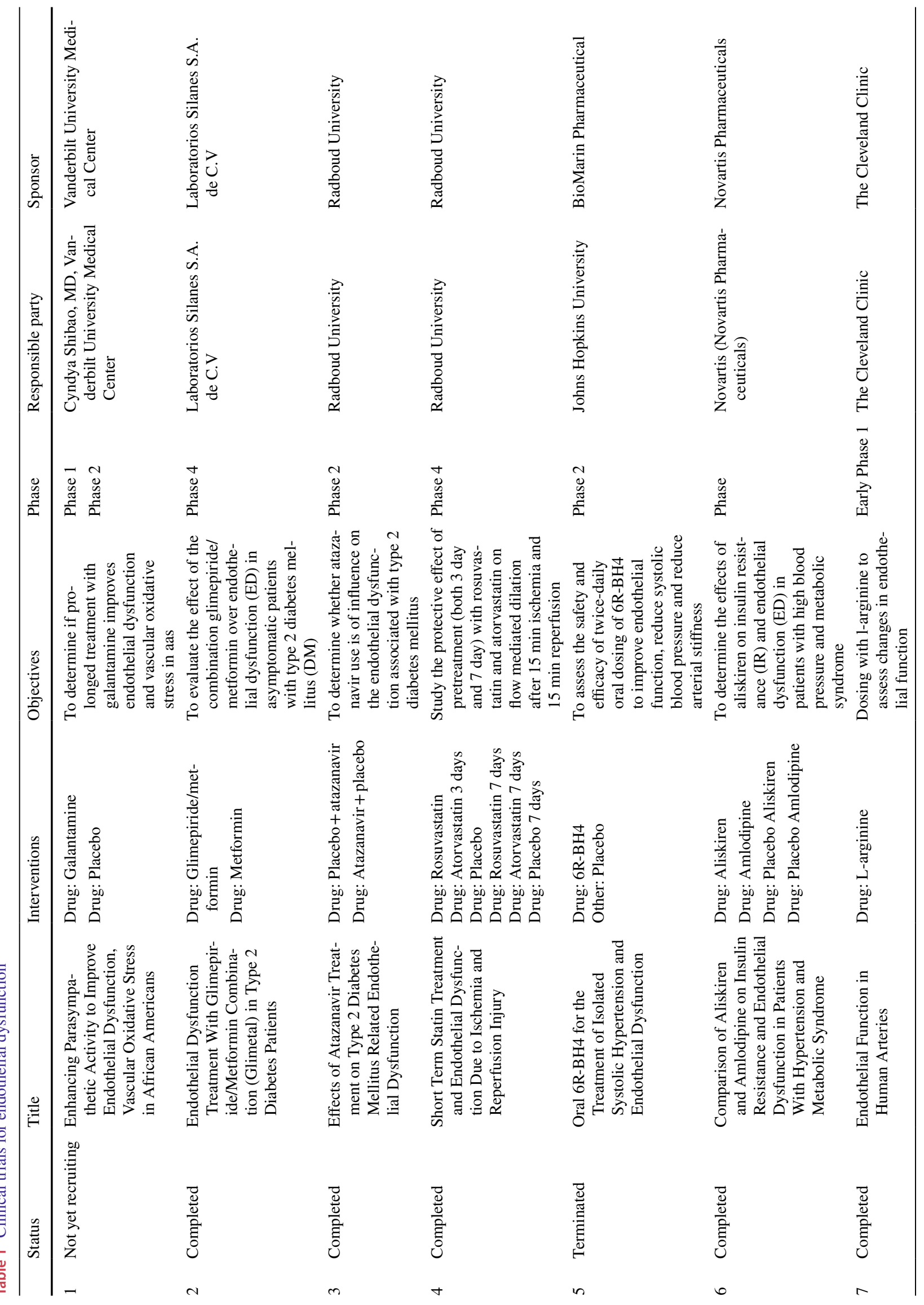




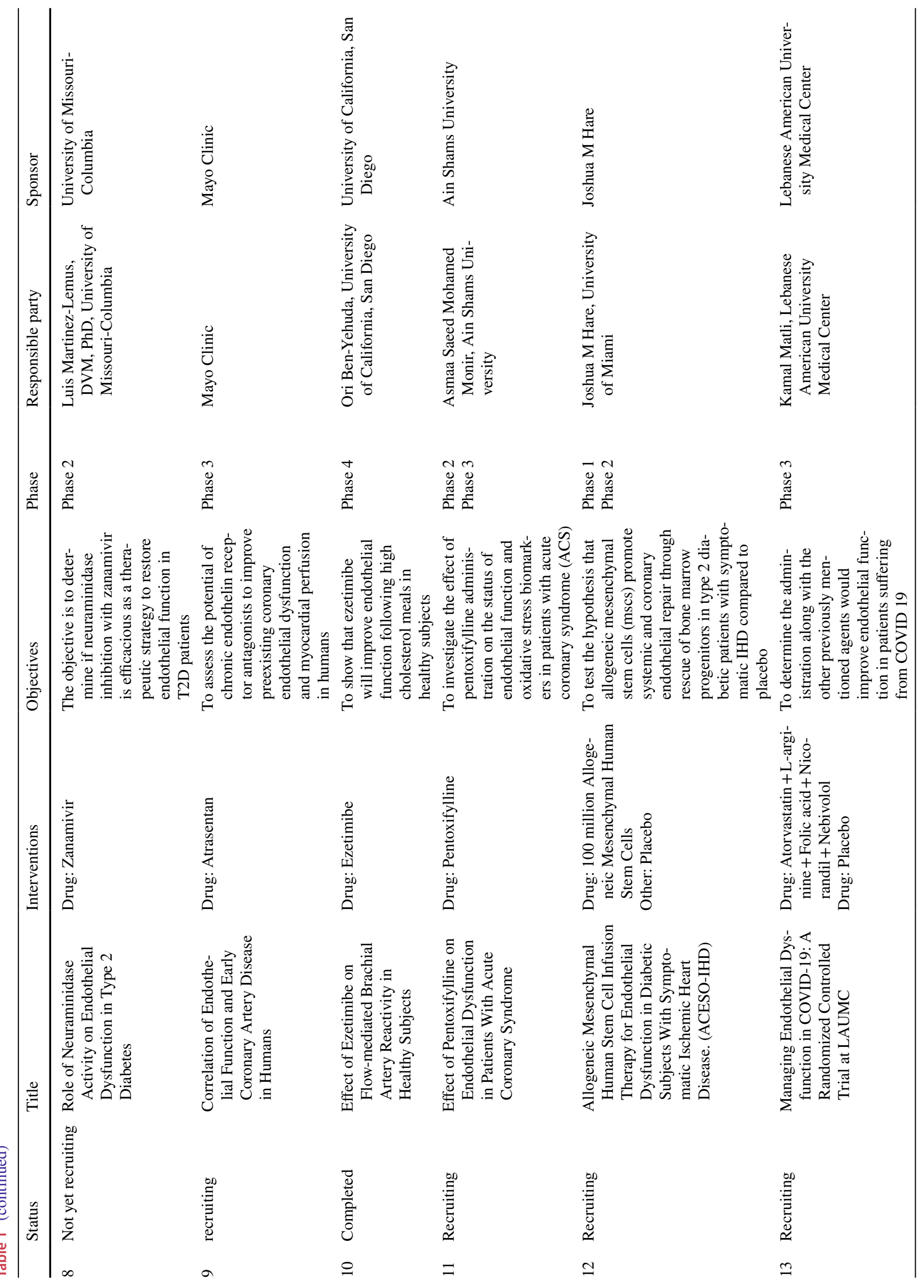




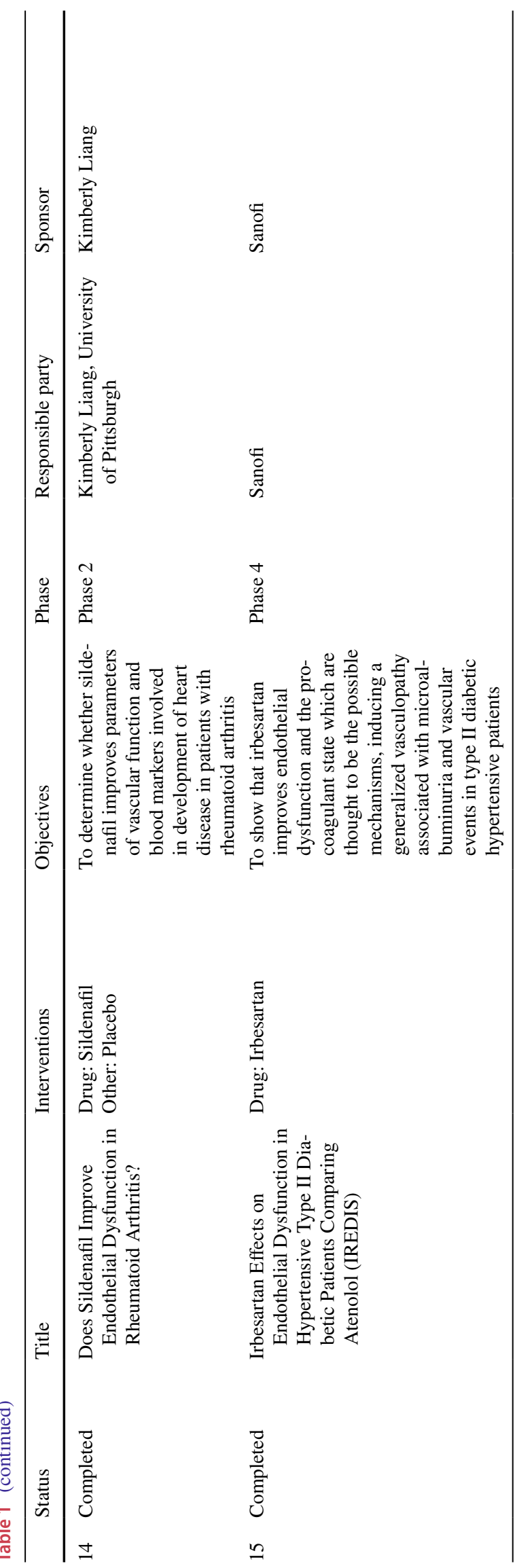

Overall, there are many types of drugs and new strategies to treat endothelial dysfunction in clinical trials. However, the mechanism of endothelial dysfunction is still not fully understood. Moreover, there is still a lack of effective drugs that specifically target injured endothelium. Therefore, it is imperative to develop novel therapies to retard or reverse the endothelial injury and prevent vascular diseases.

\section{Conclusion}

In conclusion, physical exercise could induce multiple beneficial effects in the restoration of endothelial dysfunction, including the augmentation of NO bioavailability, reduction of oxidative stress, increasing of circulating EPC, inhibition of pro-inflammatory cytokines, activation of IRS1-PI3KAKT signaling, elevation of AMPK/PPAR $\delta$ cascade and SIRT1 activity, and regulation of many types of miRNAs. These key exercise-protection sensors, such as SIRT1 and miR-126, could be used as novel therapeutic targets for the treatment of injured endothelium. Nevertheless, these underlying mechanisms identified so far do not fully enlighten all exercise-induced pathways which exert endothelial protection. Efforts are still needed to deepen the understanding of how exercise exerts beneficial effects in improving the injured endothelium, and novel key exercise sensors are still needed to be further investigated.

Funding This work was supported by the grants from the National Key Research and Development Project (2018YFE0113500 to J.X.), National Natural Science Foundation of China (82020108002 and 81911540486 to J.X.), Innovation Program of Shanghai Municipal Education Commission (2017-01-07-00-09-E00042 to J.X.), the grant from Science and Technology Commission of Shanghai Municipality (20DZ2255400 and 18410722200 to J.X., 21ZR1422700 to J.G), and the "Dawn" Program of Shanghai Education Commission (19SG34 to J.X.).

\section{Declarations}

Ethical Approval This article does not contain any studies with human participants or animals performed by any of the authors.

Conflict of Interest The authors declare no competing interests.

\section{References}

1. Augustin, H. G., Kozian, D. H., \& Johnson, R. C. (1994). Differentiation of endothelial cells: Analysis of the constitutive and activated endothelial cell phenotypes. BioEssays: news and reviews in molecular, cellular and developmental biology, 16, 901-906. 
2. Loukas, M., Clarke, P., Tubbs, R. S., Kapos, T., \& Trotz, M. (2008). The His family and their contributions to cardiology. International Journal of Cardiology, 123, 75-78.

3. Luscher, T. F., \& Barton, M. (1997). Biology of the endothelium. Clinical cardiology, 20, II-3-10.

4. Jaffe, E. A. (1987). Cell biology of endothelial cells. Human Pathology, 18, 234-239.

5. Godo, S., \& Shimokawa, H. (2017). Endothelial functions. Arteriosclerosis, Thrombosis, and Vascular Biology, 37, e108-e114.

6. Michiels, C. (2003). Endothelial cell functions. Journal of Cellular Physiology, 196, 430-443.

7. Mombouli, J. V., \& Vanhoutte, P. M. (1999). Endothelial dysfunction: From physiology to therapy. Journal of Molecular and Cellular Cardiology, 31, 61-74.

8. Davignon, J., \& Ganz, P. (2004). Role of endothelial dysfunction in atherosclerosis. Circulation, 109, III27-32.

9. Moncada, S., \& Higgs, E. A. (2006). The discovery of nitric oxide and its role in vascular biology. British Journal of Pharmacology. https://doi.org/10.1038/sj.bjp.0706458

10. Palmer, R. M., Ferrige, A. G., \& Moncada, S. (1987). Nitric oxide release accounts for the biological activity of endotheliumderived relaxing factor. Nature, 327, 524-526.

11. Emoto, N., Vignon-Zellweger, N., Lopes, R. A., Cacioppo, J., Desbiens, L., Kamato, D., Leurgans, T., Moorhouse, R., Straube, J., Wurm, R., et al. (2014). 25 years of endothelin research: The next generation. Life sciences, 118, 77-86.

12. Galley, H. F., \& Webster, N. R. (2004). Physiology of the endothelium. British Journal of Anaesth, 93, 105-113.

13. Yamazaki, Y., \& Kanekiyo, T. (2017). Blood-brain barrier dysfunction and the pathogenesis of Alzheimer's disease. International Journal of Molecular Sciences. https://doi.org/10.3390/ ijms 18091965

14. Booth, F. W., Roberts, C. K., \& Laye, M. J. (2012). Lack of exercise is a major cause of chronic diseases. Comprehensive Physiology, 2, 1143-1211.

15. Duvivier, B., Bolijn, J. E., Koster, A., Schalkwijk, C. G., Savelberg, H., \& Schaper, N. C. (2018). Reducing sitting time versus adding exercise: Differential effects on biomarkers of endothelial dysfunction and metabolic risk. Scientific Reports. https://doi. org/10.1038/s41598-018-26616-w

16. Anderson, T. J., Uehata, A., Gerhard, M. D., Meredith, I. T., Knab, S., Delagrange, D., Lieberman, E. H., Ganz, P., Creager, M. A., Yeung, A. C., et al. (1995). Close relation of endothelial function in the human coronary and peripheral circulations. Journal of the American College of Cardiology, 26, 1235-1241.

17. Scicchitano, P., Cortese, F., Gesualdo, M., De Palo, M., Massari, F., Giordano, P., \& Ciccone, M. M. (2019). The role of endothelial dysfunction and oxidative stress in cerebrovascular diseases. Free Radical Research, 53, 579-595.

18. Karoli, N. A., \& Rebrov, A. P. (2019). Endothelial dysfunction in patients with chronic obstructive pulmonary disease in combination with coronary heart disease. Terapevticheskii Arkhiv, 91, 22-26.

19. Brutsaert, D. L., Fransen, P., Andries, L. J., De Keulenaer, G. W., \& Sys, S. U. (1998). Cardiac endothelium and myocardial function. Cardiovascular Research, 38, 281-290.

20. Smiljic, S. (2017). The clinical significance of endocardial endothelial dysfunction. Medicina (Kaunas, Lithuania), 53, 295-302.

21. Tang, D. H., Bai, S., Li, X. L., Yao, M., Gong, Y. J., Hou, Y. J., Li, J., \& Yang, D. S. (2019). Improvement of microvascular endothelial dysfunction induced by exercise and diet is associated with microRNA-126 in obese adolescents. Microvascular Research, 123, 86-91.

22. Cecchi, F., Sgalambro, A., Baldi, M., Sotgia, B., Antoniucci, D., Camici, P. G., Sciagra, R., \& Olivotto, I. (2009).
Microvascular dysfunction, myocardial ischemia, and progression to heart failure in patients with hypertrophic cardiomyopathy. Journal of Cardiovascular Translational Research, 2 , 452-461.

23. Brutsaert, D. L. (2003). Cardiac endothelial-myocardial signaling: Its role in cardiac growth, contractile performance, and rhythmicity. Physiological Reviews, 83, 59-115.

24. Qiu, J., Li, J., \& He, T. C. (2011). Endothelial cell damage induces a blood-alveolus barrier breakdown in the development of radiation-induced lung injury. Asia-Pacific Journal of Clinical Oncology, 7, 392-398.

25. Good, R. B., Gilbane, A. J., Trinder, S. L., Denton, C. P., Coghlan, G., Abraham, D. J., \& Holmes, A. M. (2015). Endothelial to mesenchymal transition contributes to endothelial dysfunction in pulmonary arterial hypertension. American Journal of Pathology, 185, 1850-1858.

26. Graves, S. I., \& Baker, D. J. (2020). Implicating endothelial cell senescence to dysfunction in the ageing and diseased brain. Basic \& Clinical Pharmacology \& Toxicology, 127, 102-110.

27. Wardlaw, J. M., Smith, C., \& Dichgans, M. (2019). Small vessel disease: Mechanisms and clinical implications. Lancet Neurology, 18, 684-696.

28. Poggesi, A., Pasi, M., Pescini, F., Pantoni, L., \& Inzitari, D. (2016). Circulating biologic markers of endothelial dysfunction in cerebral small vessel disease: A review. Journal of Cerebral Blood Flow and Metabolism, 36, 72-94.

29. Jourde-Chiche, N., Fakhouri, F., Dou, L., Bellien, J., Burtey, S., Frimat, M., Jarrot, P. A., Kaplanski, G., Le Quintrec, M., Pernin, V., et al. (2019). Endothelium structure and function in kidney health and disease. Nature Reviews Nephrology, 15, 87-108.

30. Jankauskas, S. S., Andrianova, N. V., Alieva, I. B., Prusov, A. N., Matsievsky, D. D., Zorova, L. D., Pevzner, I. B., Savchenko, E. S., Pirogov, Y. A., Silachev, D. N., et al. (2016). Dysfunction of kidney endothelium after ischemia/reperfusion and its prevention by mitochondria-targeted antioxidant. Biochemistry (Moscow), $81,1538-1548$.

31. Malyszko, J. (2010). Mechanism of endothelial dysfunction in chronic kidney disease. Clinica Chimica Acta, 411, 1412-1420.

32. Hammoutene, A., \& Rautou, P. E. (2019). Role of liver sinusoidal endothelial cells in non-alcoholic fatty liver disease. Journal of Hepatology, 70, 1278-1291.

33. Rockey, D. C. (2015). Endothelial dysfunction in advanced liver disease. American Journal of the Medical Sciences, 349, 6-16.

34. Poisson, J., Lemoinne, S., Boulanger, C., Durand, F., Moreau, R., Valla, D., \& Rautou, P. E. (2017). Liver sinusoidal endothelial cells: Physiology and role in liver diseases. Journal of Hepatology, 66, 212-227.

35. Bernardo, B. C., Ooi, J. Y. Y., Weeks, K. L., Patterson, N. L., \& McMullen, J. R. (2018). Understanding key mechanisms of exercise-induced cardiac protection to mitigate disease: Current knowledge and emerging concepts. Physiological Reviews, 98, $419-475$.

36. Rocha, B., Rodrigues, A. R., Tomada, I., Martins, M. J., Guimaraes, J. T., Gouveia, A. M., Almeida, H., \& Neves, D. (2018). Energy restriction, exercise and atorvastatin treatment improve endothelial dysfunction and inhibit miRNA-155 in the erectile tissue of the aged rat. Nutrition \& Metabolism. https://doi.org/ 10.1186/s12986-018-0265-Z

37. La Favor, J. D., Anderson, E. J., Dawkins, J. T., Hickner, R. C., \& Wingard, C. J. (2013). Exercise prevents Western diet-associated erectile dysfunction and coronary artery endothelial dysfunction: Response to acute apocynin and sepiapterin treatment. American Journal of Physiology-Regulatory Integrative and Comparative Physiology, 305, R423-R434. 
38. Lee, S., Park, Y., \& Zhang, C. (2011). Exercise training prevents coronary endothelial dysfunction in type 2 diabetic mice. American Journal of Biomedical Sciences, 3, 241-252.

39. Pi, X., Xie, L., \& Patterson, C. (2018). Emerging roles of vascular endothelium in metabolic homeostasis. Circulation Research, 123, 477-494.

40. Wong, B. W., Marsch, E., Treps, L., Baes, M., \& Carmeliet, P. (2017). Endothelial cell metabolism in health and disease: Impact of hypoxia. EMBO Journal, 36, 2187-2203.

41. Eelen, G., de Zeeuw, P., Simons, M., \& Carmeliet, P. (2015). Endothelial cell metabolism in normal and diseased vasculature. Circulation Research, 116, 1231-1244.

42. Cannon, M. S. (1984). A histochemical study of the metabolism of rat renal arteries and arterioles. Angiology, 35, 129-136.

43. Cook, B. H., Granger, H. J., \& Taylor, A. E. (1977). Metabolism of coronary arteries and arterioles: A histochemical study. Microvascular Research, 14, 145-159.

44. Byts' Iu, V., and Ataman, A. V. (1989). Energy metabolism in arteries and veins in modelling epinephrine damage to the vascular wall. Patol Fiziol Eksp Ter, 63-66.

45. Sarelius, I. H., Cohen, K. D., \& Murrant, C. L. (2000). Role for capillaries in coupling blood flow with metabolism. Clinical and Experimental Pharmacology and Physiology, 27, 826-829.

46. Menghini, R., Casagrande, V., Iuliani, G., Rizza, S., Mavilio, M., Cardellini, M., \& Federici, M. (2020). Metabolic aspects of cardiovascular diseases: Is FoxO1 a player or a target? International Journal of Biochemistry and Cell Biology, 118, 105659.

47. Wilhelm, K., Happel, K., Eelen, G., Schoors, S., Oellerich, M. F., Lim, R., Zimmermann, B., Aspalter, I. M., Franco, C. A., Boettger, T., et al. (2016). FOXO1 couples metabolic activity and growth state in the vascular endothelium. Nature, 529, 216-220.

48. Hariharan, N., Maejima, Y., Nakae, J., Paik, J., Depinho, R. A., \& Sadoshima, J. (2010). Deacetylation of FoxO by Sirt1 plays an essential role in mediating starvation-induced autophagy in cardiac myocytes. Circulation Research, 107, 1470-1482.

49. Rudnicki, M., Abdifarkosh, G., Nwadozi, E., Ramos, S. V., Makki, A., Sepa-Kishi, D. M., Ceddia, R. B., Perry, C. G., Roudier, E., \& Haas, T. L. (2018). Endothelial-specific FoxO1 depletion prevents obesity-related disorders by increasing vascular metabolism and growth. elife. https://doi.org/10.7554/eLife. 39780.

50. Celermajer, D. S., Sorensen, K. E., Gooch, V. M., Spiegelhalter, D. J., Miller, O. I., Sullivan, I. D., Lloyd, J. K., \& Deanfield, J. E. (1992). Non-invasive detection of endothelial dysfunction in children and adults at risk of atherosclerosis. Lancet, 340, 1111-1115.

51. Takase, B., Uehata, A., Fujioka, T., Kondo, T., Nishioka, T., Isojima, K., Satomura, K., Ohsuzu, F., \& Kurita, A. (2001). Endothelial dysfunction and decreased exercise tolerance in interferon-alpha therapy in chronic hepatitis C: Relation between exercise hyperemia and endothelial function. Clinical Cardiology, 24, 286-290.

52. Huang, P. H., Leu, H. B., Chen, J. W., Cheng, C. M., Huang, C. Y., Tuan, T. C., Ding, P. Y. A., \& Lin, S. J. (2004). Usefulness of attenuated heart rate recovery immediately after exercise to predict endothelial dysfunction in patients with suspected coronary artery disease. American Journal of Cardiology, 93, 10-13.

53. Kuvin, J. T., Patel, A. R., Sliney, K. A., Pandian, N. G., Sheffy, J., Schnall, R. P., Karas, R. H., \& Udelson, J. E. (2003). Assessment of peripheral vascular endothelial function with finger arterial pulse wave amplitude. American Heart Journal, 146, 168-174.

54. Boos, C. J., Balakrishnan, B., \& Lip, G. Y. H. (2008). The effects of exercise stress testing on soluble E-selectin, von Willebrand factor, and circulating endothelial cells as indices of endothelial damage/dysfunction. Annals of Medicine, 40, 66-73.
55. Boos, C. J., Lip, G. Y., \& Blann, A. D. (2006). Circulating endothelial cells in cardiovascular disease. Journal of the American College of Cardiology, 48, 1538-1547.

56. Wang, L., Wang, J., Cretoiu, D., Li, G., \& Xiao, J. (2020). Exercise-mediated regulation of autophagy in the cardiovascular system. Journal of Sport and Health Science, 9, 203-210.

57. Luan, X., Tian, X. Y., Zhang, H. X., Huang, R., Li, N., Chen, P. J., \& Wang, R. (2019). Exercise as a prescription for patients with various diseases. Journal of Sport and Health Science, 8 , 422-441.

58. Gielen, S., Schuler, G., \& Hambrecht, R. (2001). Exercise training in coronary artery disease and coronary vasomotion. Circulation, 103, E1-6. https://doi.org/10.1161/01.cir.103.1.e1

59. De Keulenaer, G. W., Segers, V. F. M., Zannad, F., \& Brutsaert, D. L. (2017). The future of pleiotropic therapy in heart failure. Lessons from the benefits of exercise training on endothelial function. European Journal of Heart Failure, 19, 603-614.

60. Wang, R. W., Tian, H. L., Guo, D. D., Tian, Q. Q., Yao, T., \& Kong, X. X. (2020). Impacts of exercise intervention on various diseases in rats. Journal of Sport and Health Science, 9, 211-227.

61. Downey, R. M., Liao, P. Z., Millson, E. C., Quyyumi, A. A., Sher, S., \& Park, J. (2017). Endothelial dysfunction correlates with exaggerated exercise pressor response during whole body maximal exercise in chronic kidney disease. American Journal of Physiology-Renal Physiology, 312, F917-F924.

62. La Favor, J. D., Dubis, G. S., Yan, H., White, J. D., Nelson, M. A., Anderson, E. J., \& Hickner, R. C. (2016). Microvascular endothelial dysfunction in sedentary, obese humans is mediated by NADPH oxidase: Influence of exercise training. Arteriosclerosis, Thrombosis, and Vascular Biology, 36, 2412-2420.

63. Schuler, G., Adams, V., \& Goto, Y. (2013). Role of exercise in the prevention of cardiovascular disease: Results, mechanisms, and new perspectives. European Heart Journal, 34, 1790-1799.

64. Seo, D. Y., Ko, J. R., Jang, J. E., Kim, T. N., Youm, J. B., Kwak, H. B., Bae, J. H., Kim, A. H., Ko, K. S., Rhee, B. D., et al. (2019). Exercise as a potential therapeutic target for diabetic cardiomyopathy: Insight into the underlying mechanisms. International Journal of Molecular Sciences. https://doi.org/10.3390/ ijms20246284

65. Vona, M., Codeluppi, G. M., Iannino, T., Ferrari, E., Bogousslavsky, J., \& von Segesser, L. K. (2009). Effects of different types of exercise training followed by detraining on endothelium-dependent dilation in patients with recent myocardial infarction. Circulation, 119, 1601-1608.

66. Gevaert, A. B., Beckers, P. J., Van Craenenbroeck, A. H., Lemmens, K., Van De Heyning, C. M., Heidbuchel, H., Vrints, C. J., \& Van Craenenbroeck, E. M. (2019). Endothelial dysfunction and cellular repair in heart failure with preserved ejection fraction: Response to a single maximal exercise bout. European Journal of Heart Failure, 21, 125-127.

67. Djohan, A. H., Sia, C. H., Lee, P. S., \& Poh, K. K. (2018). Endothelial progenitor cells in heart failure: An authentic expectation for potential future use and a lack of universal definition. Journal of Cardiovascular Translational Research, 11, 393-402.

68. Asahara, T., Murohara, T., Sullivan, A., Silver, M., van der Zee, R., Li, T., Witzenbichler, B., Schatteman, G., \& Isner, J. M. (1997). Isolation of putative progenitor endothelial cells for angiogenesis. Science, 275, 964-967.

69. Kaushik, K., \& Das, A. (2019). Endothelial progenitor cell therapy for chronic wound tissue regeneration. Cytotherapy, 21, 1137-1150.

70. Qiao, J., Qi, K., Chu, P., Mi, H., Yang, N., Yao, H., Xia, Y., Li, Z., Xu, K., \& Zeng, L. (2015). Infusion of endothelial progenitor 
cells ameliorates liver injury in mice after haematopoietic stem cell transplantation. Liver International, 35, 2611-2620.

71. Zhao, Q., Liu, Z., Wang, Z., Yang, C., Liu, J., \& Lu, J. (2007). Effect of prepro-calcitonin gene-related peptide-expressing endothelial progenitor cells on pulmonary hypertension. Annals of Thoracic Surgery, 84, 544-552.

72. Ming, G. F., Tang, Y. J., Hu, K., Chen, Y., Huang, W. H., \& Xiao, J. (2016). Visfatin attenuates the ox-LDL-induced senescence of endothelial progenitor cells by upregulating SIRT1 expression through the PI3K/Akt/ERK pathway. International Journal of Molecular Medicine, 38, 643-649.

73. Subramaniyam, V., Waller, E. K., Murrow, J. R., Manatunga, A., Lonial, S., Kasirajan, K., Sutcliffe, D., Harris, W., Taylor, W. R., Alexander, R. W., et al. (2009). Bone marrow mobilization with granulocyte macrophage colony-stimulating factor improves endothelial dysfunction and exercise capacity in patients with peripheral arterial disease. American Heart Journal, 158, 53-60.

74. Recchioni, R., Marcheselli, F., Antonicelli, R., Lazzarini, R., Mensa, E., Testa, R., Procopio, A. D., \& Olivieri, F. (2016). Physical activity and progenitor cell-mediated endothelial repair in chronic heart failure: Is there a role for epigenetics? Mechanisms of Ageing and Development, 159, 71-80.

75. Sandri, M., Adams, V., Gielen, S., Linke, A., Lenk, K., Krankel, N., Lenz, D., Erbs, S., Scheinert, D., Mohr, F. W., et al. (2005). Effects of exercise and ischemia on mobilization and functional activation of blood-derived progenitor cells in patients with ischemic syndromes: Results of 3 randomized studies. Circulation, 111, 3391-3399.

76. Steiner, S., Niessner, A., Ziegler, S., Richter, B., Seidinger, D., Pleiner, J., Penka, M., Wolzt, M., Huber, K., Wojta, J., et al. (2005). Endurance training increases the number of endothelial progenitor cells in patients with cardiovascular risk and coronary artery disease. Atherosclerosis, 181, 305-310.

77. Schlager, O., Giurgea, A., Schuhfried, O., Seidinger, D., Hammer, A., Groger, M., Fialka-Moser, V., Gschwandtner, M., Koppensteiner, R., \& Steiner, S. (2011). Exercise training increases endothelial progenitor cells and decreases asymmetric dimethylarginine in peripheral arterial disease: A randomized controlled trial. Atherosclerosis, 217, 240-248.

78. Brehm, M., Picard, F., Ebner, P., Turan, G., Bolke, E., Kostering, M., Schuller, P., Fleissner, T., Ilousis, D., Augusta, K., et al. (2009). Effects of exercise training on mobilization and functional activity of blood-derived progenitor cells in patients with acute myocardial infarction. European Journal of Medical Research, 14, 393-405.

79. Bei, Y., Wang, L., Ding, R., Che, L., Fan, Z., Gao, W., Liang, Q., Lin, S., Liu, S., Lu, X., et al. (2021). Animal exercise studies in cardiovascular research: Current knowledge and optimal design-A position paper of the Committee on Cardiac Rehabilitation Chinese, Medical Doctors' Association. Journal of Sport and Health Science. https://doi.org/10.1016/j.jshs.2021. 08.002

80. Hambrecht, R., Wolf, A., Gielen, S., Linke, A., Hofer, J., Erbs, S., Schoene, N., \& Schuler, G. (2000). Effect of exercise on coronary endothelial function in patients with coronary artery disease. New England Journal of Medicine, 342, 454-460.

81. Luk, T. H., Dai, Y. L., Siu, C. W., Yiu, K. H., Chan, H. T., Lee, S. W., Li, S. W., Fong, B., Wong, W. K., Tam, S., et al. (2012). Effect of exercise training on vascular endothelial function in patients with stable coronary artery disease: A randomized controlled trial. European Journal of Preventive Cardiology, 19 , 830-839.

82. Edwards, D. G., Schofield, R. S., Lennon, S. L., Pierce, G. L., Nichols, W. W., \& Braith, R. W. (2004). Effect of exercise training on endothelial function in men with coronary artery disease. American Journal of Cardiology, 93, 617-620.

83. Gokce, N., Vita, J. A., Bader, D. S., Sherman, D. L., Hunter, L. M., Holbrook, M., O’Malley, C., Keaney, J. F., Jr., \& Balady, G. J. (2002). Effect of exercise on upper and lower extremity endothelial function in patients with coronary artery disease. American Journal of Cardiology, 90, 124-127.

84. Adams, V., Linke, A., Krankel, N., Erbs, S., Gielen, S., MobiusWinkler, S., Gummert, J. F., Mohr, F. W., Schuler, G., \& Hambrecht, R. (2005). Impact of regular physical activity on the $\mathrm{NAD}(\mathrm{P}) \mathrm{H}$ oxidase and angiotensin receptor system in patients with coronary artery disease. Circulation, 111, 555-562.

85. Hambrecht, R., Adams, V., Erbs, S., Linke, A., Krankel, N., Shu, Y., Baither, Y., Gielen, S., Thiele, H., Gummert, J. F., et al. (2003). Regular physical activity improves endothelial function in patients with coronary artery disease by increasing phosphorylation of endothelial nitric oxide synthase. Circulation, 107, 3152-3158.

86. Hosokawa, S., Hiasa, Y., Takahashi, T., \& Itoh, S. (2003). Effect of regular exercise on coronary endothelial function in patients with recent myocardial infarction. Circulation Journal, 67, 221-224.

87. Belardinelli, R., Mucaj, A., Lacalaprice, F., Solenghi, M., Seddaiu, G., Principi, F., Tiano, L., \& Littarru, G. P. (2006). Coenzyme Q10 and exercise training in chronic heart failure. European Heart Journal, 27, 2675-2681.

88. Adamopoulos, S., Parissis, J., Kroupis, C., Georgiadis, M., Karatzas, D., Karavolias, G., Koniavitou, K., Coats, A. J., \& Kremastinos, D. T. (2001). Physical training reduces peripheral markers of inflammation in patients with chronic heart failure. European Heart Journal, 22, 791-797.

89. Mancini, D. M., Walter, G., Reichek, N., Lenkinski, R., McCully, K. K., Mullen, J. L., \& Wilson, J. R. (1992). Contribution of skeletal muscle atrophy to exercise intolerance and altered muscle metabolism in heart failure. Circulation, 85, 1364-1373.

90. Hwang, M. H., \& Kim, S. (2014). Type 2 diabetes: Endothelial dysfunction and exercise. Journal of Exercise Nutrition \& Biochemistry, 18, 239-247.

91. Liese, A. D., Ma, X. G., Maahs, D. M., \& Trilk, J. L. (2013). Physical activity, sedentary behaviors, physical fitness, and their relation to health outcomes in youth with type 1 and type 2 diabetes: A review of the epidemiologic literature. Journal of Sport and Health Science, 2, 21-38.

92. Leung, F. P., Yung, L. M., Laher, I., Yao, X., Chen, Z. Y., \& Huang, Y. (2008). Exercise, vascular wall and cardiovascular diseases: An update (Part 1). Sports Medicine, 38, 1009-1024.

93. Yung, L. M., Laher, I., Yao, X., Chen, Z. Y., Huang, Y., \& Leung, F. P. (2009). Exercise, vascular wall and cardiovascular diseases: An update (part 2). Sports Medicine, 39, 45-63.

94. Sixt, S., Beer, S., Bluher, M., Korff, N., Peschel, T., Sonnabend, M., Teupser, D., Thiery, J., Adams, V., Schuler, G., et al. (2010). Long- but not short-term multifactorial intervention with focus on exercise training improves coronary endothelial dysfunction in diabetes mellitus type 2 and coronary artery disease. European Heart Journal, 31, 112-119.

95. Cheang, W. S., Wong, W. T., Zhao, L., Xu, J., Wang, L., Lau, C. W., Chen, Z. Y., Ma, R. C., Xu, A., Wang, N., et al. (2017). PPARdelta is required for exercise to attenuate endoplasmic reticulum stress and endothelial dysfunction in diabetic mice. Diabetes, 66, 519-528.

96. Dong, Y., Zhang, M., Wang, S., Liang, B., Zhao, Z., Liu, C., Wu, M., Choi, H. C., Lyons, T. J., \& Zou, M. H. (2010). Activation of AMP-activated protein kinase inhibits oxidized LDL-triggered endoplasmic reticulum stress in vivo. Diabetes, 59, 1386-1396.

97. Davis, B. J., Xie, Z., Viollet, B., \& Zou, M. H. (2006). Activation of the AMP-activated kinase by antidiabetes drug metformin 
stimulates nitric oxide synthesis in vivo by promoting the association of heat shock protein 90 and endothelial nitric oxide synthase. Diabetes, 55, 496-505.

98. Enkhjargal, B., Godo, S., Sawada, A., Suvd, N., Saito, H., Noda, K., Satoh, K., \& Shimokawa, H. (2014). Endothelial AMP-activated protein kinase regulates blood pressure and coronary flow responses through hyperpolarization mechanism in mice. Arteriosclerosis, Thrombosis, And Vascular Biology, 34, 1505-1513.

99. Cheang, W. S., Tian, X. Y., Wong, W. T., Lau, C. W., Lee, S. S., Chen, Z. Y., Yao, X., Wang, N., \& Huang, Y. (2014). Metformin protects endothelial function in diet-induced obese mice by inhibition of endoplasmic reticulum stress through 5 , adenosine monophosphate-activated protein kinase-peroxisome proliferator-activated receptor delta pathway. Arteriosclerosis, Thrombosis, and Vascular Biology, 34, 830-836.

100. Lee, C. H., Olson, P., Hevener, A., Mehl, I., Chong, L. W., Olefsky, J. M., Gonzalez, F. J., Ham, J., Kang, H., Peters, J. M., et al. (2006). PPARdelta regulates glucose metabolism and insulin sensitivity. Proceedings of the National Academy of Sciences, 103, 3444-3449.

101. Narkar, V. A., Downes, M., Yu, R. T., Embler, E., Wang, Y. X., Banayo, E., Mihaylova, M. M., Nelson, M. C., Zou, Y., Juguilon, H., et al. (2008). AMPK and PPARdelta agonists are exercise mimetics. Cell, 134, 405-415.

102. Lauer, T., Heiss, C., Balzer, J., Kehmeier, E., Mangold, S., Leyendecker, T., Rottler, J., Meyer, C., Merx, M. W., Kelm, M., et al. (2008). Age-dependent endothelial dysfunction is associated with failure to increase plasma nitrite in response to exercise. Basic Research in Cardiology, 103, 291-297.

103. Margaritis, M., Sanna, F., \& Antoniades, C. (2017). Statins and oxidative stress in the cardiovascular system. Current Pharmaceutical Design. https://doi.org/10.2174/138161282366617 0926130338

104. Park, J. H., Iemitsu, M., Maeda, S., Kitajima, A., Nosaka, T., \& Omi, N. (2008). Voluntary running exercise attenuates the progression of endothelial dysfunction and arterial calcification in ovariectomized rats. Acta Physiologiae Plantarum, 193, 47-55.

105. Maeda, S., Tanabe, T., Miyauchi, T., Otsuki, T., Sugawara, J., Iemitsu, M., Kuno, S., Ajisaka, R., Yamaguchi, I., \& Matsuda, M. (2003). Aerobic exercise training reduces plasma endothelin-1 concentration in older women. Journal of Applied Physiology, 95, 336-341.

106. Maeda, S., Tanabe, T., Otsuki, T., Sugawara, J., Iemitsu, M., Miyauchi, T., Kuno, S., Ajisaka, R., \& Matsuda, M. (2004). Moderate regular exercise increases basal production of nitric oxide in elderly women. Hypertension Research: Official Journal of the Japanese Society of Hypertension, 27, 947-953.

107. Harvey, P. J., Picton, P. E., Su, W. S., Morris, B. L., Notarius, C. F., \& Floras, J. S. (2005). Exercise as an alternative to oral estrogen for amelioration of endothelial dysfunction in postmenopausal women. American Heart Journal, 149, 291-297.

108. Xu, M., Duan, Y., \& Xiao, J. (2019). Exercise improves the function of endothelial cells by MicroRNA. Journal of Cardiovascular Translational Research, 12, 391-393.

109. Wang, L., Lv, Y., Li, G., \& Xiao, J. (2018). MicroRNAs in heart and circulation during physical exercise. Journal of Sport and Health Science, 7, 433-441.

110. Zhang, J., Zhao, F., Yu, X., Lu, X., \& Zheng, G. (2015). MicroRNA-155 modulates the proliferation of vascular smooth muscle cells by targeting endothelial nitric oxide synthase. International Journal of Molecular Sciences, 35, 1708-1714.

111. Sun, H. X., Zeng, D. Y., Li, R. T., Pang, R. P., Yang, H., Hu, Y. L., Zhang, Q., Jiang, Y., Huang, L. Y., Tang, Y. B., et al. (2012). Essential role of microRNA-155 in regulating endotheliumdependent vasorelaxation by targeting endothelial nitric oxide synthase. Hypertension, 60, 1407-1414.
112. Tang, S. T., Wang, F., Shao, M., Wang, Y., \& Zhu, H. Q. (2017). MicroRNA-126 suppresses inflammation in endothelial cells under hyperglycemic condition by targeting HMGB1. Vascular Pharmacology, 88, 48-55.

113. van Balkom, B. W., de Jong, O. G., Smits, M., Brummelman, J., den Ouden, K., de Bree, P. M., van Eijndhoven, M. A., Pegtel, D. M., Stoorvogel, W., Wurdinger, T., et al. (2013). Endothelial cells require miR-214 to secrete exosomes that suppress senescence and induce angiogenesis in human and mouse endothelial cells. Blood, 121, 3997-4006.

114. Yang, B. Y., Li, S. Z., Zhu, J., Huang, S. M., Zhang, A. H., Jia, Z. J., Ding, G. X., \& Zhang, Y. (2020). miR-214 protects against uric acid-induced endothelial cell apoptosis. Frontiers in Medicine (Lausanne). https://doi.org/10.3389/fmed.2020. 00411

115. Li, S., Xie, Y., Yang, B., Huang, S., Zhang, Y., Jia, Z., Ding, G., \& Zhang, A. (2020). MicroRNA-214 targets COX-2 to antagonize indoxyl sulfate (IS)-induced endothelial cell apoptosis. Apoptosis, 25, 92-104.

116. Wang, S., Liao, J. W., Huang, J. H., Yin, H. G., Yang, W. Y., \& Hu, M. (2018). miR-214 and miR-126 were associated with restoration of endothelial function in obesity after exercise and dietary intervention. Journal of Applied Biomedicine, 16, 34-39.

117. Chamorro-Jorganes, A., Araldi, E., Penalva, L. O., Sandhu, D., Fernandez-Hernando, C., \& Suarez, Y. (2011). MicroRNA-16 and microRNA-424 regulate cell-autonomous angiogenic functions in endothelial cells via targeting vascular endothelial growth factor receptor-2 and fibroblast growth factor receptor-1. Arteriosclerosis, Thrombosis, and Vascular Biology, 31, $2595-2606$.

118. Fernandes, T., Casaes, L., Soci, U., Silveira, A., Gomes, J., Barretti, D., Roque, F., \& Oliveira, E. (2018). Exercise training restores the cardiac microrna-16 levels preventing microvascular rarefaction in obese Zucker rats. Obesity Facts, 11, 15-24.

119. Cai, Y., Xie, K. L., Zheng, F., \& Liu, S. X. (2018). Aerobic exercise prevents insulin resistance through the regulation of $\mathrm{miR}-492 /$ resistin axis in aortic endothelium. Journal of Cardiovascular Translational Research, 11, 450-458.

120. Meng, S., Cao, J., Zhang, X., Fan, Y., Fang, L., Wang, C., Lv, Z., Fu, D., \& Li, Y. (2013). Downregulation of microRNA-130a contributes to endothelial progenitor cell dysfunction in diabetic patients via its target Runx3. PLoS ONE. https://doi.org/10.1371/ journal.pone.0068611

121. Olivieri, F., Lazzarini, R., Recchioni, R., Marcheselli, F., Rippo, M. R., Di Nuzzo, S., Albertini, M. C., Graciotti, L., Babini, L., Mariotti, S., et al. (2013). MiR-146a as marker of senescenceassociated pro-inflammatory status in cells involved in vascular remodelling. Age, 35, 1157-1172.

122. Cirilli, I., Silvestri, S., Marcheggiani, F., Olivieri, F., Galeazzi, R., Antonicelli, R., Recchioni, R., Marcheselli, F., Bacchetti, T., Tiano, L., et al. (2019). Three months monitored metabolic fitness modulates cardiovascular risk factors in diabetic patients. Diabetes \& Metabolism Journal, 43, 893-897.

123. Kureishi, Y., Luo, Z., Shiojima, I., Bialik, A., Fulton, D., Lefer, D. J., Sessa, W. C., \& Walsh, K. (2000). The HMG-CoA reductase inhibitor simvastatin activates the protein kinase Akt and promotes angiogenesis in normocholesterolemic animals. Nature Medicine, 6, 1004-1010.

124. Gong, X., Ma, Y., Ruan, Y., Fu, G., \& Wu, S. (2014). Longterm atorvastatin improves age-related endothelial dysfunction by ameliorating oxidative stress and normalizing eNOS/iNOS imbalance in rat aorta. Experimental Gerontology, 52, 9-17.

125. Farquharson, C. A., Butler, R., Hill, A., Belch, J. J., \& Struthers, A. D. (2002). Allopurinol improves endothelial dysfunction in chronic heart failure. Circulation, 106, 221-226. 
126. Wyss, C. A., Koepfli, P., Namdar, M., Siegrist, P. T., Luscher, T. F., Camici, P. G., \& Kaufmann, P. A. (2005). Tetrahydrobiopterin restores impaired coronary microvascular dysfunction in hypercholesterolaemia. European Journal of Nuclear Medicine and Molecular Imaging, 32, 84-91.

127. Melandri, G., Semprini, F., Cervi, V., Candiotti, N., Palazzini, E., Branzi, A., \& Magnani, B. (1993). Benefit of adding low molecular weight heparin to the conventional treatment of stable angina pectoris. A double-blind, randomized, placebo-controlled trial. Circulation, 88, 2517-2523.

128. Rosengart, T. K., Lee, L. Y., Patel, S. R., Sanborn, T. A., Parikh, M., Bergman, G. W., Hachamovitch, R., Szulc, M., Kligfield, P. D., Okin, P. M., et al. (1999). Angiogenesis gene therapy: Phase I assessment of direct intramyocardial administration of an adenovirus vector expressing VEGF121 cDNA to individuals with clinically significant severe coronary artery disease. Circulation, 100, 468-474.

129. Rajagopalan, S., Shah, M., Luciano, A., Crystal, R., \& Nabel, E. G. (2001). Adenovirus-mediated gene transfer of $\operatorname{VEGF}(121)$ improves lower-extremity endothelial function and flow reserve. Circulation, 104, 753-755.

Publisher's Note Springer Nature remains neutral with regard to jurisdictional claims in published maps and institutional affiliations. 